\title{
Synthesis of MK-8831
}

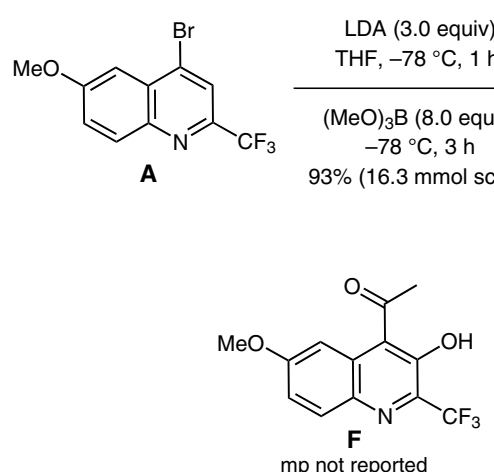

$\mathrm{mp}$ not reported<smiles>COc1ccc2nc(C)c(OC)c(Br)c2c1</smiles>

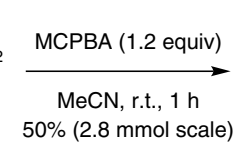<smiles>COc1ccc2nc(C(F)(F)F)c(O)c(Br)c2c1</smiles>

C

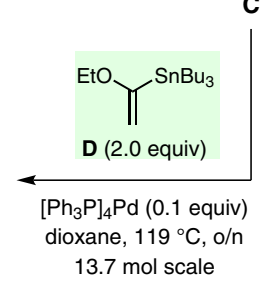

E

Gategory

Synthesis of Natural

Products and

Potential Drugs

\section{Key words}

MK-8831

HCV NS3/4a

protease inhibitors

spirocycles

macrocycles

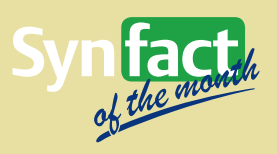

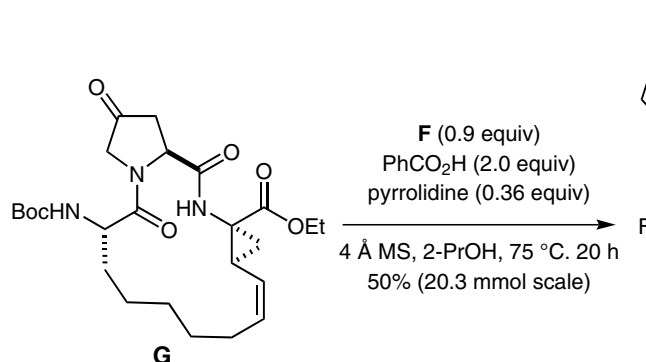

WO 2014025736

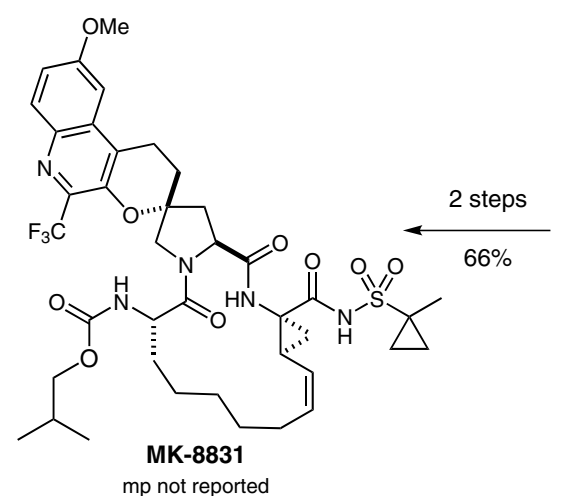

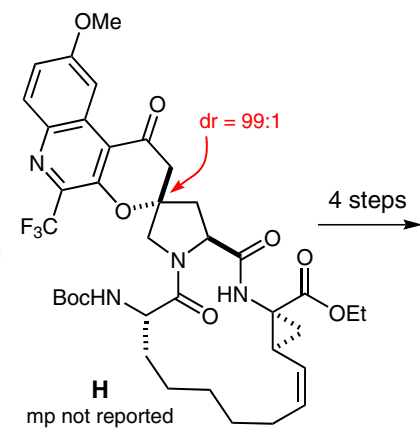

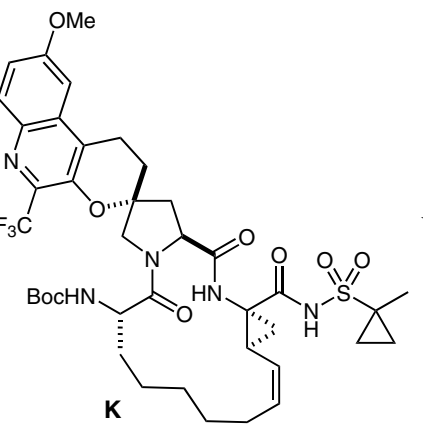

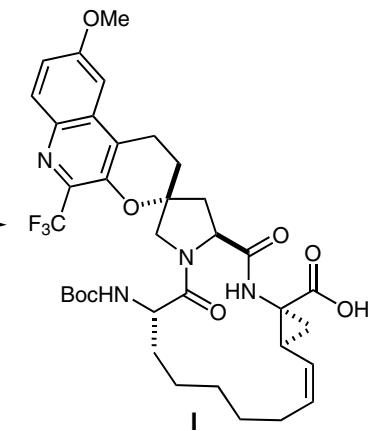

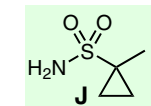

1. CDI (1.7 equiv)

THF, $70^{\circ} \mathrm{C}, 3 \mathrm{~h}$

2. $\mathbf{J}(2.5$ equiv)

$\mathrm{DBU}$ (2.5 equiv)

$50^{\circ} \mathrm{C}, \mathrm{o} / \mathrm{n}$

$56 \%$ ( $4.7 \mathrm{mmol}$ scale)

Significance: A Merck team has devised a route to HCV NS3/4a protease inhibitors containing a spirocyclic proline core. Optimization of the structure-activity relationships resulted in the identification of the clinical candidate MK-8831 with excellent pan-genotypic activity and safety profile.
Comment: Ketone $\mathbf{F}$ was cyclized with the previously reported macrocyclic prolinone $\mathbf{G}$ employing benzoic acid and pyrrolidine. Initial conditions gave very poor yields, but the optimized methods gave spirocycle $\mathbf{H}$ in $50 \%$ yield and high levels of diastereoselectivity $(\mathrm{dr}=99: 1)$. 